\title{
Los concursos de arte escolar: Una modalidad ideológica de libre mercado
}

\author{
JuLio FloRes HeRNÁNDEZ \\ FLACSO, Guatemala
}

Resumen: Es un hecho comprobado que los concursos son un mecanismo de reproducción social de las especies artísticas que como producciones simbólicas se insertan en las sociedades modernas. Los concursos reproducen la expresión artística, pero devienen como mecanismos de reproducción ideológica de libre mercado dentro de los circuitos del arte impartido a nivel escolar. El problema surge cuando estos concursos son patrocinados por empresas de capital nacional o transnacional, y bajo patrocinios financieros que buscan insertarse en el mercado de los jóvenes consumidores dentro de las escuelas, es donde cabe preguntarse si, ¿Es legítimo que los sistemas educativos permitan tal cosa, teniendo como fin principal la exploración de la expresión artística bajo premisas de mercado acordadas por las empresas privadas, con apego a la promoción de marcas y a otros dispositivos de hegemonía cultural con fines económicos? La observación de tres concursos escolares en Guatemala y su proceso de realización entre estudiantes de educación media bajo la categoría de industrias culturales incrustadas en los aparatos ideológicos del Estado, intenta dar cuenta de los mecanismos utilizados para la reproducción de un imaginario de éxito bajo premisas económicas de libre mercado, en detrimento de la función expresiva y comunicativa del arte.

Abstract: It is a fact that talent competitions are mechanisms of art reproduction that are introduced into modern societies as symbolic productions. Talent competitions generate movement in the artistic world but at the same time they have turned into mechanisms of free market ideology reproduction in the art teaching circles at school level. The main problem arises when these competitions are sponsored by national or international corporations that provide financial sponsorship with the purpose of introducing themselves into the market of young school consumers. This is the moment when comes up the question if it is legitimate for the educational system to allows having as a primary goal the exploration of artistic expression under premises set up by private companies, with brands promotion and other cultural hegemony devices attached to it for economical purposes. The research done on three school talent competitions in Guatemala and the realization process in High school students under the category of cultural industries inserted 
on the ideological apparatus of the State, tries to show the mechanisms used for the reproduction of a successful ideal under free market economy premises, to the detriment of expressive and communicative functions of art.

Palabras clave: Concurso, ideología, escuela, expresión artística, industria cultural, libre mercado
Key words: Competition, ideology, school, artistic expressions, cultural industries, free market

\section{Introducción}

Un muchacho se inscribe a un concurso, le han dicho que canta bien o que toca bien su instrumento, cosa que lo mueve al deseo de alcanzar el éxito como cantante o instrumentista. Es posible que la frase principal que le han dicho a este muchacho es: "usted tiene talento", lo que ya es un gran porcentaje ganado en ese largo camino que le espera para alcanzar el éxito deseado.

El mismo caso se produce en muchas escuelas o dentro de las familias como consecuencia de la proliferación de concursos que, sobre las expresiones artísticas, se realizan en las sociedades modernas. Los muchachos pasan a ser parte de un mecanismo sistémico que la industria cultural utiliza para hacer circular toda clase de productos de consumo de masas, como confites, dulces, galletas, bebidas carbonatadas y edulcoradas, ropa, calzado, jabones, accesorios de higiene íntima, instrumentos musicales y ofertas académicas.

El asunto que ocupa este estudio es el proceso mediante el cual estos concursos han Ilegado a ser parte de la cotidianidad o del interés de muchos jóvenes que aspiran a alcanzar el éxito artístico musical por su medio. Además, la manera como un imaginario ${ }^{1}$ se construye para crear la ilusión de ese éxito y cómo este proceso es llevado a las escuelas, bajo la mirada permisiva de los sistemas educativos que, en lugar de propiciar un ejercicio de la expresión artística liberadora, creativa y socializadora, como se acusa en su discurso curricular, promueve los consumos mencionados arriba, bajo mecanismos ideológicos de libre mercado.

\section{Arte en la escuela ¿para qué?}

El Currículo Nacional Base (CNB) que rige el sistema educativo guatemalteco contempla el área de Expresión Artística que está dividida en cuatro subáreas que son: música, danza, teatro y artes plásticas, y busca atender a la necesidad de una construcción del sentir, el apreciar 
y el crear todo lo que surge del fenómeno del arte como producto humano con carácter simbólico.

Este CNB responde al proceso de Reforma Educativa que se está llevando a cabo en Guatemala desde finales de los años 90 y que es producto de los Acuerdos de Paz firmados en 1996, luego de casi cuatro décadas de guerra interna bautizada con el eufemismo de "conflicto armado", como una puerta que permitiría negar los futuros juicios políticos a los excesos cometidos por el Estado guatemalteco con su máxima expresión; el genocidio. Dentro de ese marco, el CNB contempló la implementación de la asignatura Expresión Artística, encaminada a ofrecer "una oportunidad para la comunicación, la expresión y apreciación de la vida (...) la expresión artística es progresiva, trascendente, socializadora, equitativa, participativa y vivencial" (Ministerio de Educación, 2006, p. 120).

En este sentido, la expresión artística se pinta como una herramienta valiosa para la construcción de un orden simbólico que mediante el uso de los sonidos, el movimiento, la actuación, el color, la forma y el volumen permitan una comunicación abierta, una expresión y apreciación de todo lo que la vida en sus diversas dimensiones provea a la sociedad como producción simbólica expresada en una canción, una pintura, una danza o una obra teatral.

Al hacer más específico este análisis, es preciso enfocarlo directamente a la producción simbólica que hay en la música. Una pregunta que flota en el transcurso de este estudio proviene de la teoría específica del arte como comunicación y expresión de ideas concretas a través de los sonidos, y convoca la duda sobre los mecanismos que utiliza la música para que esos sonidos se transformen en ideas por sí mismas al ser despojados del sentido que el intérprete les otorgó en el momento de su construcción, es decir, cabe la pregunta: ¿lo que emite una comunicación musical son los sonidos tal cual, o el mensaje está más bien en todo el recurso expresivo del cuerpo que el músico ejercita al momento de producirlos?

Lo anterior surge ante la compleja construcción simbólica que se teje en los concursos de música, donde lo que se califica no es necesariamente la producción sonora del participante, ya que son más importantes, por lo menos así lo parece, otras esferas como la expresión corporal, el dominio del escenario, el vestuario, el atractivo sexual o sex appeal, el carisma y la extravagancia. 


\section{Concursos de arte e ideología}

El concurso es competencia pero también es fiesta. Es una buena ocasión para el ocio, pero no el ocio creativo, sino un ocio puro para el consumo. Se interrumpen las clases para asistir a la presentación de los amigos, de los compañeros, se inventan porras y se hacen pancartas de apoyo para infundir ánimo a los participantes. Las consignas del concurso se hacen escuchar, ruedan las imágenes, las luces surten su efecto luminiscente para enfocar a las futuras estrellas, todos están felices y todos quieren ganar, pues el premio es codiciado, aunque no sea efectivo y únicamente consista en un simple diploma. Pero los premios no son para todos, solamente para los elegidos. A pesar de eso, allí están todos los que tuvieron el aplomo, la valentía y el coraje de soportar los nervios y los posibles abucheos de sus oponentes, aunque al final solamente queden los triunfadores; esos elegidos por los dioses que vivirán en carne propia la gloria de salir retratados en algún medio que todos verán. Con todo, siempre quedará ganas de más, porque la vida continúa y si no es hoy puede ser mañana, y porque a lo mejor aquellos dos que desde la escuela de Frankfurt cuestionaban a la industria cultural tuvieron razón al señalar que "hoy las masas engañadas creen en el mito del éxito aún más que los afortunados. Las masas tienen lo que quieren y reclaman obstinadamente la ideología mediante la cual se las esclaviza" (Horkheimer y Adorno, 1998, p. 8).

Es notable entonces que, estando así las cosas, el concurso esté pensado desde un fino entramado cultural:

Organizado en un sistema de máquinas productoras de bienes simbólicos que son transmitidos a sus públicos consumidores: es lo que hace la escuela con sus alumnos, la prensa con sus lectores, la televisión con sus audiencias y la iglesia con sus fieles. (Brunner, 1993, p. 21)

El concurso es además una analogía de la continua competencia que representa la sobrevivencia para las sociedades humanas, y el entramado que lo teje obedece a una dinámica que necesariamente debe ser excluyente. El participante llega con la ilusión de ser incluido entre los ganadores, aunque siempre corre el riesgo de la exclusión que sufren los perdedores, así se cumple la máxima: 'muchos son los Ilamados, y pocos los escogidos'. Y sobre las bases de los concursos se construye una normatividad que funciona 
como fachada del espectáculo, pues la exclusión radica en no dejar pasar a quien no encaja dentro de la espectacularidad de la especie artística que se está calificando.

Esas dinámicas de selección son normales dentro de los concursos que se observan en los medios televisivos, y cabe señalar que son estos los que marcan un parámetro, un marco referencial del nivel de atención que se le presta a la espectacularidad en la música. Independientemente del género musical que se califique, el participante debe llenar toda una gama de dominios escénicos, debe ser muy histriónico y capaz de arrasar con cualquier posibilidad de aburrimiento que pueda tener el público que es convertido en consumidor del espectáculo. Ahí hay una ideología del espectáculo como consumo de masas que, en la esfera de los medios de comunicación, es hasta cierto punto normal. Los medios se sostienen de ese espectáculo que a su vez sostiene al consumidor promedio que siempre está atento a lo nuevo, a lo innovador, aunque el supuesto de lo creativo sea una especie reciclada de estilos, formas e interpretaciones musicales de las mismas canciones. Lo verdaderamente creativo no cabe en esta idea del espectáculo.

Pero si esta es la manera como los medios reproducen un consumo masivo de arte reciclado, las preguntas necesarias son: ¿qué hacen estos concursos operando dentro del sistema escolar?, ¿en qué momento pasa la escuela a ser el operador de cazador de talentos para la industria musical?, y si esto ha sido posible, ¿en qué medida repercute su presencia en el arte escolar?, y ¿cómo se transfiere a ideología de libre mercado como marco institucional dentro de la escuela?

Para caracterizar la ideología de libre mercado ${ }^{2}$ operando dentro de un concurso de arte escolar, es necesario ponderar primero a qué tipo de concurso se refiere el estudio y quiénes son sus promotores o patrocinadores. Puesto que los tres casos que se analizan obedecen a premisas analíticas que caben dentro de lo que Althusser (1970) denominó "Aparatos Ideológicos del Estado", es decir; la escuela, la iglesia y los medios, en tanto que se diferencian unos de otros según la institución que promueve cada concurso.

A continuación se enlistan según la institución promotora:

A. Concurso Juventud Don Bosco, Colegio Don Bosco.

B. Concurso Municipal de Coros Escolares, Municipalidad de Guatemala.

C. Concurso Talent Tour, periódico Prensa Libre. 


\section{A. Concurso Juventud Don Bosco, Colegio Don Bosco}

Realizado desde 1969, este concurso es parte de una tradición que se conoce como la Semana del Movimiento Juventud Don Bosco, dentro del Colegio Salesiano del mismo nombre en la Ciudad de Guatemala. Incluye diversas ramas de participación y se realiza a mitad del año. Su carácter religioso le hace cumplir fielmente con su papel de aparato ideológico que refuerza los discursos institucionales sobre los valores de colaboración, solidaridad y fe, según los preceptos de los salesianos emanados de San Juan Bosco.

En el transcurso de este concurso es notable que el discurso institucional está presente en todo momento, y que su base primordial radica en que la participación debe ir enfocada hacia esos preceptos que se califican como valores y principios cristianos. No obstante, la competencia es asumida por los estudiantes como una manera de alcanzar cierto prestigio entre sus compañeros. Generalmente los premios consisten en una plaqueta y un diploma de participación, y se clasifican en un orden de primer a tercer lugar. Aunque lo ideológico aquí está enfocado hacia el aspecto religioso, es evidente que el prestigio se asume como un reconocimiento de cierta capacidad que excluye a los que no lograron ganarlo, aunque tengan la ilusoria satisfacción de haber participado. Sobre los participantes es importante resaltar que en su mayoría pertenecen a la modalidad que en Guatemala se conoce como colegios privados, es decir, empresas educativas de capital familiar o institucional. De esta forma, las escuelas de carácter público o del Estado, quedan mayoritariamente excluidas de participar en estos concursos.

\section{B. Concurso Municipal de Coros Escolares, Municipalidad de Guatemala}

Organizado dentro de la Escuela Municipal, es parte de otras actividades que se desarrollan en el marco de la celebración de la fundación de la ciudad y en conmemoración de la fiesta patronal de la ciudad, dedicada a la Virgen de la Asunción el 15 de agosto de cada año. Según sus organizadores, su realización busca fomentar la participación escolar. Es evidente que al ocurrir dentro de las instalaciones de una escuela municipal, se interiorizan los emblemas, los colores y las figuras de personajes de influencia en la vida municipal. Se fortifica de este modo su función de aparato ideológico al promover estos elementos dentro de un imaginario de poder que se refuerza con las imágenes del político de turno que gobierna la alcaldía, así 
como la constante circulación de iconografías, logotipos y colores asociados a la imagen de su administración. Este tipo de actividades son divulgadas por diversos medios, como la página electrónica de la municipalidad, o bien a través de la revista Transmetro que la alcaldía produce para divulgar su gestión, y que también funciona como una propaganda gratuita para la autoridad de turno. Cabe mencionar que mientras esto se escribe, el alcalde de la ciudad lleva varias administraciones valiéndose de estos medios a través de fideicomisos poco transparentes y con nula fiscalización.

Aunque hay un porcentaje mínimo de centros educativos del Estado que participan, como ya se dijo, la mayoría son los Ilamados colegios de tipo privado, lo que hace evidentes las diferencias de clase social cuando tienen acceso a este tipo de actividad. Principalmente, los premios consisten en un diploma de participación más una plaqueta o trofeo para los tres primeros lugares.

\section{Concurso Talent Tour, periódico Prensa Libre}

Realizado por el periódico Prensa Libre, un consorcio de medios de comunicación que posee gran influencia en el país, comenzó a mediados de la década de los 90 a divulgarse como una plataforma para que los jóvenes estudiantes de Educación Media pudieran expresarse a través de la música. Se divulgó desde el principio en una revista juvenil patrocinada por el periódico que se llamaba Aula 2mil, luego Aula 2.0 y ahora solamente Aula. La principal característica de este concurso consiste en que si bien los otros dos son institucionales y se realizan dentro del marco de algunas festividades, cumplen su función ideológica y atienden a quienes se acercan para participar, mientras que el Talent Tour llega a los centros educativos, pues cuenta con todo un aparato de marketing para el efecto. Los participantes pertenecen únicamente al sector de la educación privada, es decir, a los colegios que se constituyen en factor de mercado, en ellos es donde todos los martes se distribuye la revista Aula de forma gratuita para los estudiantes, aunque no participen del concurso.

Durante un mes, el concurso llega a los colegios para realizar la selección de los ganadores de cada colegio que participarán en la gran final. Llegar a la gran final es toda una oportunidad para quienes logran pasar los filtros de selección. Mientras tanto, al hacer la selección cada participante está ofreciendo su arte al público y al jurado calificador, entonces circulan panfletos comerciales, actos y competencias para ganar productos de los patrocinadores. Esto sucede tanto a nivel de colegio como en la gran final. Los jurados calificadores son personajes de la farándula que 
ya gozan de reconocimiento mediático y especialistas en las áreas a calificar. Similar a los anteriores, los premios consisten en un diploma, un trofeo y un kit de productos de los patrocinadores, aunque es probable que lo más valioso sea el momento de tomarse las fotos que aparecerán en la revista, tal como las grandes estrellas que se ven en los medios.
Dentro de las ediciones del concurso observadas para el presente estudio, los patrocinadores fueron marcas de alimentos, productos para la salud y una institución privada de Educación Superior de reconocida influencia en la vida académica guatemalteca.

\section{Ilusión, escuelas privadas y libre mercado: una conclusión}

En los concursos analizados es fácil observar que hay hilos invisibles que mueven su funcionamiento, aunque los dos primeros no llegan a tener una influencia más allá de quienes se acercan a ellos. Es notable como el tercero utiliza toda su maquinaria para hacerse llegar y reproducir sus mecanismos de mercado dentro de los centros educativos. El problema radica en la función de la escuela, ya que en el currículo se enuncia que está para propiciar la comunicación, la expresión y la apreciación de la vida, pero al permitir la realización de mecanismos de mercado dentro de las escuelas se fomenta la competencia, la cual se instituye como la premisa principal y unívoca de sobrevivencia. El participante se ilusiona con ganar un concurso, y tiene la posibilidad de hacerlo pero también puede ser excluido por no contar con las herramientas y accesorios que le son impuestos como requisito, lo que elimina la otra premisa curricular que dice que la expresión artística es progresiva, trascendente, socializadora, equitativa, participativa y vivencial.

Esto nos lleva a concluir lo siguiente: en 1996 se firmó la paz en Guatemala, el gobierno de turno en esa época fue el primero de corte neoliberal que hubo en el país. En ese lapso sucedió la privatización de las empresas estatales y el discurso apuntaba a la certeza de la disminución del Estado en la medida que perdería el control que podía ejercer sobre el mercado. Fue en ese mismo momento que se inició la Reforma Educativa, como parte de los Acuerdos de Paz, y así las políticas educativas permitieron que una empresa llevara el concurso a las aulas escolares de la educación privada, su brazo principal en el intento de ideologizar la educación pública para que esta también pudiera ser privatizada en la medida de un proceso que no se llevó a cabo. A cambio de ello, muchos de los espacios de la educación pública se fueron desfinanciando hasta casi hacerlos 
quebrar y se creaba la idea de lo privado como lo único que puede salvar al país de la decadencia.

Han pasado casi veinte años desde la firma de los Acuerdos de Paz, la ilusión del éxito económico y del libre mercado tiene sus altibajos en la vida política y económica del mundo globalizado. La administración del gobierno de Pérez Molina se desmoronó ante la revelación de actos de corrupción de muchos de sus principales actores, y la transición llevó al poder, paradójicamente, a un artista de la comedia. En tanto, los concursos siguen reproduciendo la ilusión del éxito artístico dentro de las escuelas privadas, y posiblemente miles de estudiantes de la educación pública podrían ser partícipes de un proceso educativo que les suministre maneras adecuadas de expresión, a través del arte escolar que tarda en llegar.

\section{Referencias}

- Althusser, L. (1970). Ideología y aparatos ideológicos de Estado. Recuperado de http://www.infoamerica.org/documentos_pdf/althusser1.pdf

- Avancso. (2015). Área de estudios sobre imaginarios. Recuperado de http://avancso.org.gt/areas-de-estudio/ area-de-estudios-sobre-imaginarios-sociales/

- Barbero, J. M. (1993). Las transformaciones del mapa: identidades, industrias y culturas. Recuperado de www.plataforma.uchile.cl

- Brunner, J.J. (1993). América Latina: cultura y modernidad. México: Grijalbo.

- Horkheimer, M., y Adorno, T. (1998). La industria cultural. Iluminismo como mistificación de masas. En Dialéctica del iluminismo. Buenos Aires: Editorial Sudamericana.

- Millones Espinosa, M. (mayo-agosto de 2013). Neoliberalismo en América Latina: una interpretación desde la ideología en Žižek. Sociológica 28, № 79, pp. 51-78.

- Ministerio de Educación. (2006). Currículo Nacional Base. Nivel Primario. Recuperado de http://www.mineduc.gob.gt/ DIGECUR/?p=CNB.asp\&t=Curriculo_Nacional_Base_CNB

- Velásquez, A. (2014). Ideología Burguesa y Democracia, una aproximación al movimiento libertario en Guatemala y sus discursos. Guatemala: Serviprensa.

- Žižek, S. (2003). El sublime objeto de la ideología. Argentina: Siglo XXI editores. 
del "como si" el desarrollo social fuera posible si se deja actuar libremente al mercado, aplicado a la ilusión del participante del concurso, quien actúa "como si" el triunfo en el concurso fuera posible con el solo hecho de participar. (Žižek, citado por Millones Espinoza, 2013, p. 60.) 